\title{
Letramento na educação infantil: o que as professoras pensam (sabem)?
}

Tatiana Santos Arruda ${ }^{1}$

\section{Resumo}

O objetivo deste artigo é investigar o que as professoras de educação infantil compreendem a respeito do letramento. Parte-se do princípio de que a educação infantil possui uma especificidade pedagógica própria e que o letramento envolve práticas sociais de leitura e escrita. A pesquisa foi realizada em uma instituição de educação infantil e teve como participantes as professoras que atuavam com crianças de quatro e cinco anos. Foram utilizados: questionários; observação e análise documental. As informações foram analisadas na perspectiva qualitativa e permitiram o entendimento que: prevaleceu a função socializadora da educação infantil; e, as professoras confundem os conceitos de letramento e alfabetização, não esclarecem as diferenças e relações entre os processos.

Palavras-chave: Educação Infantil; Letramento; Professores.

\section{Literacy in early childhood education: what do teachers know (think)?}

\begin{abstract}
The purpose of this article is to investigate what kindergarten teachers understand about literacy. It is assumed that early childhood education has its own pedagogical specificity and that literacy involves social practices of reading and writing. The research was carried out in an early childhood education institution and had as participants the teachers who worked with children of four and five years old. Were used: questionnaires; observation and document analysis. The information was analyzed in a qualitative perspective and allowed the understanding that: the socializing function of early childhood education prevailed; and, early childhood teachers confuse the concepts of literacy and do not clarify the differences and relationships between the dimensions of the literacy process. Keywords: Child Education; Literacy; Teachers.
\end{abstract}

\section{Considerações iniciais}

No Brasil, a educação infantil se constituiu, historicamente, como espaço de lutas e conflitos. Surgiu, em grande parte, como resposta às demandas sociais, em especial, em decorrência da mobilização da sociedade civil, movimento de mulheres e criança próconstituinte (ROSEMBERG, 2005), movimentos de redemocratização do país, comunitários, de trabalhadores e dos próprios profissionais da educação (BRASIL, 2010) que solicitavam o atendimento às crianças pequenas. Pouco a pouco foi modificando sua função social e, hoje, tem reconhecida a sua especificidade pedagógica (KRAMER, 2006), que está para além do caráter assistencial e lugar de guarda.

\footnotetext{
${ }^{1}$ Secretaria de Estado de Educação do Distrito Federal, Brasília, arruda.tatiana@gmail.com.
} 
A Lei de Diretrizes e Bases da Educação Nacional - LDB, Lei no 9.394/1996, inaugura a educação infantil como primeira etapa da educação básica e evidencia o caráter educativo do atendimento às crianças de zero a cinco anos. Aliado a isto, tem-se, atualmente, a busca pela universalização da educação infantil, prevista no Plano Nacional de Educação- PNE, Lei $n^{\circ}$ 13.005/2014, que propõe logo na meta 1 a efetivação do direito à educação para as crianças pequenas, quatro e cinco anos, e bem pequenas, de zero a três anos de idade.

O acesso às instituições educativas implica, assim, em reflexões e encaminhamentos pedagógicos que possibilitem, de fato, a ampliação das oportunidades de aprendizagem e desenvolvimento das crianças. Nesse sentido, surgem as questões vinculadas ao letramento, compreendido como uma das facetas da apropriação do Sistema de Escrita Alfabética, como afirma Soares (2016), e que abrange as práticas sociais de leitura e escrita.

Nessa direção, há na atual Base Nacional Comum Curricular- BNCC (BRASIL, 2017) um campo de experiência chamado "Escuta, fala, pensamento e imaginação" que privilegia a cultura oral e escrita, assim como o contato com diferentes textos escritos e gêneros literários. É possível, então, pensar em práticas educativas que favoreçam o letramento e as diversas funções sociais da escrita na educação infantil.

Para Morais, Silva e Nascimento (2020) a BNCC, em especial o campo de experiências supracitado, não explicitou, na última versão, o direito de as crianças avançarem na compreensão da escrita alfabética, mas existem indicações de práticas de leitura de textos. Estas práticas predominaram em relação às propostas de iniciação à produção de textos escritos.

O objetivo deste artigo situa-se nesse contexto de leitura e escrita e busca, de forma específica, investigar o que as professoras ${ }^{2}$ de educação infantil compreendem a respeito do letramento. As discussões acerca do letramento do ensino fundamental são recorrentes e fruto de políticas públicas que procuram ampliar a formação docente no que se refere ao processo de alfabetização e superação das mazelas do sistema de ensino. No entanto, o mesmo não pode ser dito em relação à primeira etapa da educação básica, de modo que surge a questão: o que as professoras que atuam na educação infantil entendem e sabem a respeito do letramento?

Para realizar esta investigação, será apresentado o referencial teórico sobre a educação

${ }^{2}$ Será utilizado o termo no feminino respeitando-se o gênero das participantes da pesquisa, que foram todas mulheres.

Periódico Horizontes - USF - Itatiba, SP - Brasil - e021005 
infantil e as suas funções sociais. Em seguida, o que é letramento, compreendido como práticas sociais de leitura e escrita. Para então indicar a metodologia utilizada, a abordagem privilegiada e os instrumentos usados durante o estudo exploratório: questionários, análise documental, que envolvia o planejamento, as atividades realizadas pelas crianças e a observação dos murais de sala (internos e externos).

Os resultados encontrados são apresentados e indicados juntos às discussões. Nas considerações finais do estudo há a compreensão de que, para as professoras participantes da pesquisa: a) prevaleceu a função socializadora da educação infantil; e, que, b) elas confundiram os conceitos de letramento e alfabetização e não esclareceram as diferenças e relações entre os dois conceitos.

Para o entendimento do estudo realizado serão apresentadas a seguir as bases teóricas que fundamentaram a pesquisa.

\section{A educação infantil e as suas funções sociais}

As diferentes funções sociais da educação infantil estão atreladas a própria história da constituição desta etapa da educação básica. Para Rosemberg (2005) tais funções são: a) cuidado/guarda de crianças pequenas no período em que suas mães estão no mercado de trabalho; b) educação/socialização das crianças em locais institucionais; c) compensação de "carências", sejam estas econômicas, psicológicas, culturais e/ou linguísticas; e, d) socialização visando projetos políticos nacionais, o que implica em desenvolvimento econômico e a implementação de certas ideologias.

Apesar das diferenças entre tais funções observa-se que o papel da educação infantil esteve por muito tempo atrelado de maneira mais tendenciosa à função assistencialista, de guarda e proteção das crianças enquanto as mães estavam no trabalho (KRAMER, 2003; OLIVEIRA, 2002), ou como momento preparatório para o ensino fundamental, voltando-se a "evitar" o fracasso escolar (KRAMER, 2003).

Para Kuhlmann Jr. (2003) essas funções pedagógicas vinculadas à educação infantil são influenciadas pelo poder econômico das famílias das crianças atendidas. Assim, a polarização entre a função preparatória e a assistencialista, de acordo com o referido autor, permitem às 
propostas “inaugurar o 'novo' e implantar o 'pedagógico' ou o 'educacional', nos textos, enquanto a realidade institucional permanece intocada nas questões que efetivamente discriminam a população pobre" (p.53).

O que diferencia as instituições, para o citado autor, não é a origem institucional, se vinculada à assistência social ou à secretaria de educação, nem a ausência de propósitos educativos, mas o público e a faixa etária atendida. Desse modo, o assistencialismo configurouse, na história das instituições destinadas à criança de baixa renda, como o propósito educativo de fato.

Barreto (2004) reafirma essa relação acerca da função social da educação infantil e o poder aquisitivo das famílias. Para ela, essa dupla trajetória da educação infantil de cuidado e educação ocorreu não apenas no Brasil, como também em outros países, diferenciando o trabalho pedagógico realizado com crianças de classes econômicas mais privilegiadas e as que não possuíam os mesmos recursos.

A propósito, Oliveira (2005) argumenta, ainda, que apenas quando segmentos da classe média procuraram atendimentos em creche é que as instituições de educação infantil aprofundaram a discussão a respeito de uma proposta verdadeiramente pedagógica, comprometida com o desenvolvimento das crianças e com a construção de conhecimentos.

Nessa perspectiva, autores como $\operatorname{Kramer}(2006,2003)$ têm ressaltado que a educação infantil possui uma função pedagógica específica. Não é um atendimento compensatório, nem apenas um local de proteção das crianças. Mais do que isso, esta etapa possui um papel singular na escolarização das crianças.

Na LDB (BRASIL, 1996) está explícito no artigo 29 que a primeira etapa da educação básica tem como finalidade o desenvolvimento integral da criança de até cinco anos, em seus aspectos físico, psicológico, intelectual e social. Nessa direção, as Diretrizes Curriculares Nacionais da Educação Infantil- DCNEI (BRASIL, 2010) orientam que o currículo se configura como um conjunto de práticas que procuram articular as experiências e os saberes das crianças com os conhecimentos que fazem parte do patrimônio cultural, artístico, ambiental, científico e tecnológico.

Nesse contexto, se inserem as práticas sociais de leitura e escrita como vias para acesso aos patrimônios da humanidade, possibilitando ainda a ampliação do repertório cultural das 
crianças, outras formas de ler o mundo e se aproximar de conhecimentos produzidos pelas diversas áreas da ciência, bem como oportunidades de se apropriarem de diferentes gêneros discursivos e do Sistema de Escrita Alfabética. Assim, o direito à educação infantil se configura como pedagógico, em outras palavras, com o caráter educativo.

Acrescentando argumentos ao direito à educação infantil, Rosemberg (2005) enfatiza que a busca pelo atendimento nessa etapa da educação básica está na perspectiva de que a educação infantil não produza ou reforce as desigualdades sociais já existentes, o que remete, ainda, a uma visão da criança pequena como ativa, competente, produtora de cultura, e não apenas com possibilidades futuras.

Nas DCNEI (BRASIL, 2010, p.12) há a defesa de que as crianças são sujeitos históricos e de direitos que, nas interações, relações e práticas cotidianas que vivenciam, constroem sua identidade pessoal e coletiva, brincam, imaginam, fantasiam, desejam, aprendem, observam, experimentam, narram, questionam e constroem sentidos sobre a natureza e a sociedade, produzindo cultura.

Para essas crianças ativas e produtoras de cultura é preciso um trabalho pedagógico que atenda às suas especificidades, as quais são constituídas no contexto social e cultural em que se inserem. São distintas de acordo com o meio social em que atuam e do qual participam. As práticas educativas na educação infantil precisam considerar as diversidades apresentadas pelas crianças e suas infâncias e tê-las como ponto de partida.

Nessa direção, Rocha (2002) argumenta que a forma como as crianças vivem é determinada por condições sociais, por tempos e espaços sociais próprios de cada contexto. Para a autora, "a infância não é uma só, ou seja, as crianças não vivem a infância de forma homogênea ou uniforme em nenhum dos seus aspectos: econômico, social, cultural, lúdico, alimentar e etc." (p.01).

A infância, assim, é concebida como uma categoria social e histórica, sendo simultaneamente um período da história de cada pessoa que se estende do nascimento até os 10 anos. A inserção concreta das crianças e seus papéis variam conforme a organização social (KRAMER, 2006)

Para envolver essa diversidade de crianças e infâncias, Kramer (2006) sugere que o trabalho pedagógico a ser realizado com as crianças pequenas compreenda a experiência, o 
conhecimento científico e a cultura, entendida tanto na dimensão de produção nas relações sociais cotidianas quanto de produção historicamente acumulada. O trabalho pedagógico abrange, assim, a música, literatura, dança, teatro, arte, história, cultura e cinema. É, portanto, interdisciplinar, tendo por fundamento as dimensões da cultura, ética e estética e os conhecimentos das crianças (KRAMER, 2003).

Tais considerações implicam, na sociedade contemporânea, considerar, ainda, as marcas da cultura escrita, compreendida como Galvão (2016, p.17) propõe: "como o lugar - simbólico e material - que o escrito ocupa em/para determinado grupo social, comunidade ou sociedade". Hoje, como aborda a autora, a dimensão escrita da linguagem é provavelmente uma das mais importantes, pois está presente nas diversas situações cotidianas, como rótulos de embalagens, mensagem em redes sociais, bilhetes, histórias em quadrinho, livros, revistas, jornais, peças de teatro, histórias recontadas/recitadas/lidas oralmente, placas, listas de compras, entre outros.

Inserir a cultura escrita no trabalho pedagógico na educação infantil é importante, portanto, para os processos de aprendizagem e desenvolvimento as crianças. Implica, também, em refletir acerca da heterogeneidade da cultura escrita e na compreensão do sujeito como produtor de cultura (GALVÃO, 2016).

Considerando ser a aprendizagem de crianças pequenas indiferenciada por fronteiras de assuntos, Barreto (2004) afirma que se torna inadequado um currículo estruturado por disciplinas acadêmicas, fragmentado em partes estanques. Esta compreensão exige do professor sensibilidade para "monitorar o comportamento e o progresso individual e dos pequenos grupos de crianças. Isso requer, também, uma forte consciência sobre os objetivos da aprendizagem e habilidades múltiplas para capitalizar os interesses das crianças" (p.66).

Nesse trabalho interdisciplinar, destacam-se a ampliação de saberes e conhecimentos de diferentes naturezas, promovendo a igualdade de oportunidades educacionais entre as crianças de diferentes classes sociais no que se refere ao acesso a bens culturais e às possibilidades de vivência da infância (BRASIL, 2010), e também a reflexão a respeito da cultura escrita.

Nesse sentido, as DCNEI (2010) possibilitam a compreensão de que, para a construção do trabalho pedagógico na educação infantil, é relevante contemplar as suas especificidades, partindo do pressuposto da inseparabilidade do cuidar e educar, a seleção de saberes que considerem as áreas de interesses das crianças, o seu contexto social, e ampliando suas 
possibilidades de acesso aos conhecimentos construídos pela humanidade, sem, entretanto, se restringir aos conteúdos do ensino fundamental.

A BNCC, por sua vez, especifica que é preciso pensar em intencionalidade pedagógica na educação infantil, o que consiste na proposição e organização de experiências que possibilitem às crianças conhecer a si mesmo e ao outro, bem como conhecer e compreender as relações com a natureza, com a cultura e com a produção científica. Para tanto, propõe os campos de experiências, que constituem "[...] um arranjo curricular que acolhe as situações e as experiências concretas da vida cotidiana das crianças e seus saberes, entrelaçando-os aos conhecimentos que fazem parte do patrimônio cultural" (BRASIL, 2017, p.40).

Entre os campos de experiências indicados na BNCC está "Escuta, fala, pensamento e imaginação", que se relaciona com as aprendizagens vinculadas com a cultura oral e a escrita. Segundo o documento, "[...] a imersão na cultura escrita deve partir do que as crianças conhecem e das curiosidades que deixam transparecer" (BRASIL, 2017, p.41). E, mais, indica que o contato com diversos textos escritos, permite as crianças construir hipóteses a respeito da escrita e da sua compreensão acerca da escrita como sistema de representação da língua.

Desse modo, o trabalho pedagógico na educação infantil pode e deve incluir os conhecimentos relevantes para um dado meio social, considerados importantes para a aprendizagem e o desenvolvimento das crianças. Possui, assim, a função de concretizar e tornar explícitas as suas intenções educativas e diversas faces da cultura, o que inclui a cultura escrita. Não apenas os conteúdos presentes nas diferentes áreas do saber.

Nos aspectos relativos às intenções educativas, parte-se da defesa do espaço destinado à linguagem verbal, oral e escrita, atrelada à especificidade pedagógica da educação infantil e a sua perspectiva interdisciplinar. De forma que a linguagem escrita pode ser trabalhada ao lado de outras tantas linguagens, como: plástica, corporal, musical, de faz de conta, como afirmam Brandão e Leal (2018).

Vale lembrar, então, os caminhos possíveis quanto ao trabalho com a linguagem escrita na educação infantil e que acabam por direcionar as práticas e ações docentes. Para Brandão e Leal (2018) há três principais caminhos: o primeiro refere-se à obrigação da alfabetização, em que é cobrado das crianças o domínio de certas associações grafofônicas, cópias de letras, palavras e pequenos textos. 
Para isso, prevalece o trabalho exaustivo com letras, iniciando com o reconhecimento das vogais, depois consoantes e famílias silábicas. A aquisição da leitura e escrita corresponde, assim, à aquisição de um código de transcrição do escrito para o oral e vice-versa. E para ser considerado alfabetizado, basta a criança memorizar as associações som-grafia (BRANDÃO; LEAL, 2018).

O segundo caminho possível é o letramento sem letras, que se caracteriza pela ênfase dada na educação infantil a outras linguagens, como: corporal, musical, gráfica, entre outras, em detrimento da linguagem escrita, banida do trabalho pedagógico. A alfabetização é entendida como "conteúdo escolar" e por isso deve ser proibida para as crianças. Muitos professores, diante das curiosidades acerca da leitura e escrita, reproduzem práticas de ensino que eles próprios tiveram em suas experiências escolares (BRANDÃO; LEAL, 2018).

O terceiro caminho indicado por Brandão e Leal (2018) diz respeito ao ler e escrever com significado na educação infantil, que surge como via pedagógica a partir das reflexões a respeito da especificidade pedagógica da etapa e a perspectiva sociointeracionista. Utilizando-se das palavras de Ferreiro (apud 1993), as autoras apontam para a não obrigatoriedade da alfabetização na pré-escola (termo utilizado na obra), mas indicam as múltiplas oportunidades para as crianças verem a professora ler e escrever; explorar textos escritos, semelhanças e diferenças; explorar o espaço gráfico e distinguir entre desenho e escrita, e outras oportunidades.

Com base nesse entendimento, considera-se, como afirmam Brandão e Leal (2018), a possibilidade de inserir aspectos relativos ao Sistema de Escrita Alfabética na educação infantil às práticas de letramento; assim como, às necessidades relacionadas ao desenvolvimento e às vivências da infância. De maneira que seja viabilizada para as crianças situações em que possam ter contato com a leitura e com escrita, e mais, em que brincando elas possam ingressar na cultura escrita.

Entretanto, há pesquisas que apontam para a direção contrária, como o estudo de Barros e Spinillo (2011). As autoras partiram da compreensão de que a escola tem um papel importante para os usos sociais da leitura e escrita e tinham como objetivo investigar a contribuição da educação infantil para o letramento de crianças não alfabetizadas. Em suas construções verificaram que as crianças possuíam um conhecimento limitado sobre textos e seus portadores, 
e que, apesar do tempo na educação infantil (três, dois ou um ano), esta etapa não propiciou o desenvolvimento do letramento.

De forma surpreendente Barros e Spinillo (2011) concluíram ainda que as crianças com dois e três anos de educação infantil apresentaram conhecimentos mais limitados do que aquelas que tinham cursado somente um ano ou não tiveram experiência escolar. Em outras palavras, "as práticas de educação infantil das crianças investigadas nesta pesquisa não foram capazes de contribuir para que, com o aumento da escolaridade, elas alcançassem um conhecimento mais elaborado sobre textos" (BARROS; SPINILLO, 2011, p.549).

Tais construções viabilizam reflexões acerca da função pedagógica e social da educação infantil, sobre as práticas desenvolvidas e o seu papel para os processos de aprendizagem e desenvolvimento das crianças. E mais, reflexões a respeito da compreensão das professoras e professores sobre o que é letramento.

\section{Letramento e relações com a alfabetização}

Novos conceitos surgem em decorrência de novas demandas, questões e fatos, os quais requerem também uma nova maneira de entender os processos educativos. O termo letramento se configura nesse bojo, uma nova palavra que surge a partir da necessidade de resposta as situações sociais vinculadas ao trabalho pedagógico. No Brasil, como afirma Soares (2012), em fins do século XX ocorre o aparecimento da expressão literacy, motivando a criação de "letramento".

Nesse processo histórico, percebeu-se que o termo analfabetismo não bastava, ou mesmo o seu oposto, alfabetização. De modo recente, o país passou a enfrentar esta nova "realidade social em que não basta apenas saber ler e escrever, é preciso também saber fazer uso do ler e do escrever, saber responder às exigências de leitura e escrita que a sociedade faz continuamente" (SOARES, 2012, p.20). Daí o surgimento do conceito de letramento.

Questões em torno do letramento e a sua compreensão no trabalho pedagógico, então, podem ser consideradas como um processo recente, em especial da educação infantil. Isso porque as discussões em torno desse novo conceito emergem atreladas à alfabetização, vinculadas ao ensino fundamental e às dificuldades dos estudantes em utilizar as habilidades da 
leitura e escrita nos diferentes contextos sociais.

Apesar dessa relação, cabem reflexões também na primeira etapa da educação básica, de maneira a favorecer explorações diversas da cultura escrita, segundo a especificidade pedagógica da educação infantil. Favorecendo, nessa direção, aprendizagens relacionadas às práticas sociais de leitura e escrita, a linguagem oral e escrita e aos diferentes suportes de textos presentes na sociedade.

Faz-se relevante, portanto, entender o que é letramento e a alfabetização, as suas diferenças e aproximações. As distinções entre os dois conceitos, no entanto, não estão claras no meio educacional, como afirma Marcuschi (2007). Para o autor "a expressão 'letramento' entrou na língua portuguesa em meados dos anos 1980 e hoje tornou-se bastante comum, mas nem sempre de forma clara" (2007, p.32).

A pesquisa desenvolvida por Berberian et al. (2013) corrobora a compreensão sobre a necessária distinção entre alfabetização e letramento por parte dos professores que estão nas salas de aula. No estudo realizado pelas autoras participaram 90 docentes atuantes no ensino fundamental da Rede Municipal de Ensino de diferentes cidades do Paraná. Dentre as informações construídas está que não houve diferença significante entre o conhecimento dos professores sobre a concepção de linguagem escrita, letramento, alfabetização e os motivos que levaram a incorporação do conceito de letramento no sistema educacional.

Além disso, elas verificaram que apesar de $80 \%$ dos docentes terem realizado leitura de textos sobre o letramento e $84,8 \%$ identificar diferenças entre esse conceito e a alfabetização, somente $12 \%$ estabeleceu adequada diferenciação entre os mesmos. Concluíram, ainda, que há restrições quanto ao conhecimento dos professores acerca das concepções da escrita e, assim, "limitações para o estabelecimento de associações teórico-práticas efetivas para a promoção de práticas de leitura e escrita significativas, junto ao processo de ensino/aprendizagem da língua portuguesa [...]" (BERBERIAN et al., 2013, p.1635).

Nessa perspectiva, cabem as pesquisas também no contexto da educação infantil, que representa para muitas crianças o primeiro contato com o contexto escolar e com um processo sistematizado de ensino. As discussões a respeito do que é o letramento e as suas relações com a alfabetização são necessárias com os professores que atuam na primeira etapa da educação básica, mesmo que se reconheça que não é finalidade desse momento a alfabetização dos estudantes. 
Tornam-se oportunos, assim, os esclarecimentos acerca da alfabetização, que se constituindo como uma prática social, sofreu modificações históricas e até mesmo culturais, pois cada cultura marca as suas demandas sobre esse processo. O entendimento a respeito do que é ser alfabetizado transformou-se segundo as mudanças e demandas socioculturais.

Se antes o entendimento voltava-se para mecânica da língua escrita, hoje, é consensual para professores, estudiosos e para a própria sociedade que isto não é suficiente para as demandas sociais. Décadas atrás a alfabetização se restringia a ensinar um código, a língua escrita, ou seja, direcionava-se para a habilidade de codificar a língua oral em língua escritaescrever e de decodificar a língua escrita em língua oral- ler, como afirma Soares (2007).

Posteriormente, em meados da década de 1980, ler e escrever passam a abranger também a apreensão e compreensão de significados expressos em língua escrita - a leitura, e a expressão de significados por meio da língua escrita - a escrita. Nesse contexto, a alfabetização seria um processo de compreensão e expressão de significados (SOARES, 2007).

Atualmente, compreende-se que a alfabetização, como aquisição da língua oral e escrita, é apenas um dos aspectos que integram a aprendizagem da escrita. Para Soares (2016) a aprendizagem inicial da língua escrita envolve três facetas: a) a faceta propriamente linguística da língua escrita - alfabetização; b) a faceta interativa; e, c) a faceta sociocultural. Estas duas últimas facetas são consideradas por ela como o letramento. As três facetas juntas se configuram como componentes que, desenvolvidos simultânea e indissociavelmente, definem a aprendizagem da língua escrita.

Segundo Soares (2016) a faceta linguística tem com objeto de conhecimento a apropriação do sistema alfabético-ortográfico e das convenções da escrita. Envolve a representação sonora da fala, considerada como a alfabetização. As competências visadas são a codificação e a decodificação da escrita. Nesse sentido, a alfabetização "é componente necessário, mas não suficiente, do processo de aprendizagem inicial da língua escrita" (p.346, grifo da autora).

A faceta interativa da língua escrita, por sua vez, compreende esta como veículo de interação entre as pessoas, expressão e compreensão de mensagens. Vincula-se às habilidades de compreensão, interpretação, produção de textos, enriquecimento de estruturas linguísticas, de ampliação de vocabulário, de conhecimentos a respeito das convenções a que materiais impressos seguem, dentre outros. (SOARES, 2016). 
A terceira faceta denominada como sociocultural, incluí os usos, funções e valores atribuídos à escrita em contextos socioculturais. Requer o conhecimento de fatores que condicionam esses usos, funções e valores atribuídos à escrita em diversos eventos de letramento (SOARES, 2016).

O letramento, assim, se constitui como as práticas sociais da escrita e aponta para os mais variados modos de apropriação, domínio e uso da escrita, o que está para além de uma simples forma de representação gráfica da língua (MARCUSCHI, 2007). Para o referido autor, o letramento até pode se desenvolver no cotidiano de forma espontânea, mas, em geral, caracteriza-se como a apropriação da escrita que se desenvolve em contextos formais, no processo de escolarização.

Ademais, de acordo com o autor, o letramento relaciona-se aos usos e as práticas e não especificamente às formas. Abrange, com isso, todas as formas visuais, como gráficos, fotos, mapas e todo tipo de expressão visual e pictográfica, observável em textos multimodais.

A educação infantil, assim, pode possibilitar situações pedagógicas que favoreçam o letramento das crianças, considerando sua particularidade educativa e o momento do desenvolvimento infantil. Ações como a leitura de diversos gêneros discursivos, leitura de imagens, obras artísticas, a produção de textos coletivos em que o professor é o escriba, a confecção de rotas/mapas, bem como a escrita espontânea ou inventada trazem oportunidades para as crianças ampliarem o seu repertório cultural e o acesso a conhecimento de mundo.

Estas oportunidades de aprendizagem e desenvolvimento são importantes desde a educação infantil, afinal, indicam o reconhecimento do papel ativo e produtor de cultura das crianças. Além disso, como afirma Marcuschi (2007, p.36): “a escrita é tanta uma forma de domínio da realidade no sentido de apreensão do saber e da cultura, como é também uma forma de dominação social enquanto propriedade de poucos [...]". Os investimentos em situações de letramento são, portanto, relevantes em todas as etapas da educação básica.

Nesse sentido, torna-se interessante observar que há uma diferença entre saber ler e escrever, ser alfabetizado, e viver na condição ou estado de quem sabe ler e escrever, ser letrado. Para ser considerado letrado faz-se necessário fazer uso da leitura e da escrita, envolver-se nas práticas sociais de leitura e escrita. De maneira que, a partir de tais práticas, a pessoa se torne diferente, adquira um outro estado, uma outra condição (SOARES, 2012). 
Assim, tanto para Soares (2007) como para Marcuschi (2007) existem diferenças entre letrado e iletrado, os quais não se caracterizam como polos dicotômicos, e sim como dois extremos de um contínuo, que vai de um mínimo a um máximo. Desse modo, há níveis de letramento variados, assim como há pessoas alfabetizadas que pouco fazem uso da escrita.

De fato, hoje, os usos da escrita são muito diversificados, de acordo com os indivíduos, o seu contexto social, a sua profissão e as suas necessidades. Por outro lado, a escrita é, sem dúvidas, um bem inestimável para o avanço e acesso aos conhecimentos, mas que ainda não se acha tão bem distribuída na sociedade, nem que todos podem usufruir (MARCUSCHI, 2007).

Reconhecer a importância dos diferentes usos da escrita remete à consideração de que na educação infantil é possível aproximar as crianças da leitura e da escrita, em um contexto funcional e significativo para elas, como afirmam Brandão e Leal (2018). Para as autoras, é pertinente favorecer o contato com o funcionamento do sistema de escrita alfabética e o desenvolvimento da consciência fonológica ${ }^{3}$, assim como oportunizar atividades que promovam aprendizagens acerca de gêneros discursivos orais e escritos que circulam socialmente e suas características.

No contexto das atividades oferecidas na educação infantil, Albuquerque e Leite (2018) apresentam a pesquisa de Lima e Albuquerque (apud 2009), que estudaram as práticas de ensino de leitura e escrita desenvolvidas em duas turmas desta primeira etapa. De forma breve, é possível apontar as características predominantes nestas duas turmas, as quais possibilitam a compreensão da análise das autoras.

Na turma A, sistematicamente as crianças tinham oportunidade de refletir acerca do sistema de escrita alfabética, de maneira prazerosa e lúdica. O contato com as letras ocorria com base na exploração de palavras presentes em textos que faziam parte do universo infantil, em textos lidos pela professora, ou com base na exploração dos nomes das próprias crianças. (ALBUQUERQUE; LEITE, 2018).

Na turma B, a prática da professora tinha ênfase na repetição e na memorização de letras. O ensino era transmissivo e formal das letras do alfabeto e organizava-se em uma mesma sequência de cada letra, qual seja: apresentação da letra a ser aprendida, depois palavras que

\footnotetext{
${ }^{3}$ Para maiores aprofundamentos acerca do conceito ver: MORAIS, A. Consciência fonológica na educação infantil e no ciclo de alfabetização. Belo Horizonte: Autêntica, 2019.
}

Periódico Horizontes - USF - Itatiba, SP - Brasil - e021005 
começavam com esta letra, identificação da letra, realização do treino gráfico da letra com pontinhos e cópia da letra, imprensa e cursiva (ALBUQUERQUE; LEITE, 2018).

Nas construções apontadas as autoras perceberam que: as crianças da turma A apresentaram um resultado significativamente melhor que os alunos da turma $B$, compreendendo que as letras representam a parte sonora das palavras. Enquanto as crianças da turma B, ao escreverem palavras ditadas pelas pesquisadoras, grafavam apenas uma letra para representá-las. Nas suas produções, indicaram, ainda, que desconheciam alguns princípios básicos do sistema de escrita alfabética (ALBUQUERQUE; LEITE, 2018).

$\mathrm{Na}$ conclusão desse estudo, Albuquerque e Leite (2018) defendem um processo de ensino-aprendizagem da língua escrita na escola que não seja transmissivo e exaustivo de letra e sílabas, e sim com textos, palavras e suas unidades menores, tanto gráficas quanto sonoras e a relação entre elas. Afirmam que quanto mais oportunidades favorecermos às crianças, mais elas serão desafiadas e estimuladas a se envolverem com a língua escrita, o que envolve atividades lúdicas, situações para pensarem e refletirem sobre o funcionamento da escrita alfabética e vivências em relação a leitura e escrita.

Assim, compreende-se que a apropriação do sistema alfabético-ortográfico abrange as especificidades dos processos de alfabetização e letramento e que, na educação infantil, as crianças devem ter acesso às práticas de leitura e escrita. Este entendimento, aliado aos fundamentos teóricos apresentados anteriormente embasam a pesquisa proposta.

\section{Metodologia}

A pesquisa realizada configurou-se como um estudo exploratório e teve como objetivo geral: investigar o que as professoras de educação infantil compreendem a respeito do letramento. Para isso, optou-se por desenvolver o estudo segundo a abordagem qualitativa, que pressupõe, de acordo com Lüdke e André (1986), características como: a) o ambiente natural como fonte direta de dados e o pesquisador como seu instrumento, o que implica no contato direto com o ambiente e a situação que está sendo investigada e, b) o significado que as pessoas dão às coisas e à sua vida como focos de atenção do pesquisador, o que contempla a perspectiva dos participantes. 
Integraram a pesquisa cinco professoras atuantes na primeira etapa da educação básica e que faziam parte do corpo docente de uma instituição de ensino da rede pública do Distrito Federal, no ano letivo de 2019. Esta instituição estava localizada em uma região administrativa de classe média baixa e atendia exclusivamente a educação infantil. Possuía um total de dez turmas, cinco em cada turno, divididas em: quatro turmas de atendimento às crianças de quatro anos e seis turmas compostas por crianças na faixa etária de cinco anos. Cada turma tinha em torno de vinte e um estudantes.

Os instrumentos utilizados foram três: um questionário abrangendo formação profissional e questões relacionadas às concepções das professoras a respeito da função social da educação infantil, do letramento e da alfabetização. Os questionários foram respondidos individualmente e por escrito, oportunizando a escrita livre de julgamentos e avaliações. Outra fonte de informações foram as observações semiestruturadas dos murais internos e externos das salas de aula, em que se buscou informações acerca das produções das crianças, em especial, a sua autoria e os vínculos com práticas de leitura e escrita. E o terceiro, a análise documental de atividades produzidas pelas crianças, verificando-se relações com o letramento e alfabetização. Os dois últimos instrumentos ocorreram no período de seis semanas.

A construção das informações seguiu as premissas do processo de triangulação (YIN, 2005) de fontes, que possibilita o confronto entre as construções advindas de múltiplas fontes de pesquisa, seguindo os instrumentos citados acima. Como eixos de análise foram utilizados: informações profissionais; função social da educação infantil; conceito de letramento; conceito de alfabetização. Para tanto, consideram-se as informações presentes nos instrumentos acima indicados.

\section{Resultados e discussão}

As professoras participantes deste estudo tinham em média quarenta dois anos de idade. Apenas uma professora estava na faixa dos trinta anos, e as demais tinham em torno de quarenta e sete. Esse é um dado relevante porque implica, no mínimo, em dois aspectos. O primeiro refere-se aos saberes construídos a partir das experiências docentes. É importante considerar as características das crianças de quatro e cinco anos e os desafios em promover um trabalho 
pedagógico interdisciplinar, articulado ao momento em que estão vivendo, suas curiosidades e interesses. O tempo de experiência das professoras pode contribuir para tanto.

Por outro lado, a idade das professoras está relacionada também ao tempo de magistério específico na educação infantil. Elas tinham em torno de vinte anos de atuação na educação. De forma particular, possuíam seis anos, em média, na educação infantil. Das professoras respondentes, a que tinha menor tempo de atuação, nessa etapa, contava com dois anos de experiência. A docente com maior tempo com crianças de quatro e cinco anos estava há quatorze anos nessa etapa.

Havia, portanto, um grupo de professoras com tempo significativo de experiências docentes, em especial, no ensino fundamental, etapa que se direciona para os processos de alfabetização e, de forma mais recente, também, para as práticas de letramento. As experiências que elas viveram em seu desenvolvimento profissional poderiam colaborar para a compreensão dos diferentes usos da escrita, isto é, do letramento.

Na instituição educativa, elas estavam atuando em média há um ano e meio. A professora que participou da pesquisa com maior tempo naquela instituição estava há três anos e a que tinha menor tempo, havia ingressado no ano da pesquisa. Assim, mesmo contando com um tempo significativo de experiências no magistério, as professoras tinham um curto espaço de tempo na instituição específica.

Os resultados do estudo realizado demonstraram, ainda, que $100 \%$ das professoras que integraram a pesquisa possuíam o ensino superior, o que indica, a princípio, o acesso às discussões teórico-práticas em torno do processo educativo, o que envolve discussões acerca dos processos que implicam à aprendizagem inicial da língua escrita. Das cinco docentes que responderam ao questionário, três tinham o curso superior em Pedagogia e duas fizeram outras licenciaturas.

No que se refere especificamente à Pedagogia, as atuais Diretrizes Curriculares Nacionais do curso, Resolução CNE/CP no 1, de 15 de maio de 2006, explicitam que o egresso deve estar apto para compreender, cuidar e educar de crianças de zero a cinco anos, de forma a contribuir, para o seu desenvolvimento nas dimensões, entre outras, física, psicológica, intelectual, social, conforme está no artigo quinto. Dentre as possibilidades pedagógicas, o documento indica a necessária formação dos pedagogos a respeito da educação infantil e suas especificidades, o que 
inclui as discussões sobre as práticas de leitura e escrita com as crianças (BRASIL, 2006).

Outra informação da pesquisa diz respeito à formação continuada. Apenas uma professora, das cinco respondentes, não possui pós-graduação lato sensu. Três delas fizeram a sua especialização na área de educação, de forma ampla, e uma no campo da educação especial. Nenhuma delas realizou estudos mais profundos na educação infantil.

A ausência de estudos nessa etapa é um fator relevante, uma vez que as docentes atuavam em uma instituição de atendimento exclusivo à educação infantil e, como dito acima, atuam, em média, há seis anos com crianças de quatro e cinco anos. Além disso, a universalização do acesso à primeira etapa da educação básica ainda não foi alcançada nas diferentes regiões do país, e a sua ampliação gradativa permite que professores, antes atuantes no ensino fundamental, migrem para as turmas de quatro e cinco anos.

As informações a respeito da função social da educação infantil contaram com respostas diversas como: "Base de toda a educação" (Professora E) e "trabalhar a parte motora, emocional e física como suporte para a vida!" (Professora B). Estas respostas aproximam-se da finalidade expressa na LDB e a colocação da professora B, de certa forma, indica a perspectiva de desenvolvimento integral das crianças, para além de conteúdos e do aspecto cognitivo. Entretanto, as duas professoras não explicitam o que é próprio da primeira etapa da educação básica, a sua especificidade pedagógica e importância do trabalho pedagógico envolver a formação cultural dos estudantes.

As ideias acerca da educação infantil como espaço de socialização ainda está presente nas colocações das professoras, que responderam: "Preparar, incentivar e ensinar as crianças para a vida, ajudando-as a compreender seus deveres e se apropriarem de seus direitos. Além de promover a socialização também" (Professora A). Outra professora, afirmou: "Acredito que o papel principal da educação infantil seja a socialização, a vivência das regras da escola e o letramento básico (Professora D).

As respostas das professoras $A$ e $D$ relacionam-se com o debate sobre a função socializadora das instituições de educação infantil, com a necessidade de espaços alternativos, extraparentais, de cuidado, socialização e educação das crianças. Vinculando-se, ainda, com a compreensão de que, nos últimos tempos, houve um declínio das fontes de socialização no interior do espaço doméstico (HADDAD, 2005). 
Dentre as possibilidades explicativas desse declínio estão a violência social, que impede as crianças de explorarem as suas comunidades, as ruas e as brincadeiras ao ar livre; as mudanças nas dinâmicas familiares, que devido às exigências do mercado de trabalho e a busca por melhores condições de vida, se ausentam, cada vez mais, dos momentos de lazer e cultura junto a seus filhos. Isto, aliado, ao crescente uso das tecnologias de informação e comunicação, bem como das redes sociais, distancia as crianças dos momentos de interação com familiares, outras crianças, o seu grupo social.

Ademais, para Haddad (2005), essa discussão sobre a função socializadora da educação infantil tem como pano de fundo a ideia de que o cuidado e a socialização da criança pequena "é uma tarefa a ser compartilhada entre família e poder público. Numa perspectiva histórica, ocorre um deslocamento das funções socializadoras do âmbito restrito do lar a uma esfera social mais ampla" (p.93). Nesse sentido, a autora afirma que é relevante um salto qualitativo na compreensão de que as instituições de educação infantil possuem uma multifuncionalidade, convergindo às funções sociais e educacionais.

No âmbito educacional, está a resposta da professora C que afirmou: "função essencial, pois é onde inicia o desenvolvimento acadêmico de forma lúdica do estudante". Em sua resposta, ela chama a atenção para o "desenvolvimento acadêmico", o que, se supõe, implica em ampliação de conhecimentos e acesso a leituras de mundo. Aspectos estes que devem ser alcançados por meio da "forma lúdica", isto é, de brincadeiras, diversão e envolvimento dos estudantes.

Nessa direção, Kramer (2006, p.207) afirma: “Desde Paulo Freire aprendemos que educação e pedagogia dizem respeito à formação cultural - o trabalho pedagógico precisa favorecer a experiência com o conhecimento científico e com a cultura". Para a autora, o pedagógico inclui as dimensões política, ética e estética; e a educação, como uma prática social que se constitui como outra forma de conhecimento científico.

Os cuidados necessários acerca dessa formação cultural estão em voltar o pêndulo da função social da educação infantil para a preparação para o ensino fundamental. Em 2007, esta foi a função pedagógica predominante encontrada por Corrêa (2007) em sua pesquisa de mestrado, realizada também no Distrito Federal e na primeira etapa da educação básica. Naquele momento, a pesquisadora concluiu que, para as professoras que integraram o seu 
estudo, cabia à educação infantil o desenvolvimento de capacidades cognitivas e sociais, a fim de preparar as crianças para a vida futura e sua inserção no mercado de trabalho.

Assim, considera-se que educação infantil, na sua especificidade pedagógica, tem um papel na oferta de situações educativas que favoreçam a ampliação da formação cultural, o que abrange as práticas de leitura e escrita. E com isso, o entendimento das professoras acerca da alfabetização e do letramento.

No que se refere ao letramento, as professoras trouxeram o conceito como: "é você proporcionar ao educando todos os saberes possíveis, possibilitando o acesso a todas as formas de ensino" (Professora A); e, "é a leitura de mundo, da realidade, da vida... Letramento, compreensão de cidadania." (Professora C). Nestas respostas, considera-se que não houve clareza quanto ao conceito de letramento, o qual foi confundido com "saberes possíveis" e "cidadania".

Assim, apesar de entender que o letramento permite a construção de saberes, formas diversificadas de ensino e leitura de mundo, as práticas e os usos sociais da leitura e escrita abrangem outros aspectos, como: a exploração e utilização de gêneros discursivos orais e escritos, produção de escritas inventadas e segundo a norma padrão, a interpretação de imagens, gráficos e mapas, dentre outras possibilidades educativas.

A observação dos murais internos e externos das salas de aula não indicou a realização de atividades nessa perspectiva de letramento. Ao contrário, as atividades e desenhos expostos eram produzidos de uma forma padronizada, em que cabia às crianças colorirem ou colarem adereços (fitas coloridas, palitos de picolé etc.). Os murais externos, por exemplo, tinham temáticas definidas previamente pela coordenação pedagógica e não se relacionava ao trabalho pedagógico desenvolvido.

A pouca clareza quanto ao conceito de letramento também ficou presente nas respostas de outras professoras, como: "É associar imagens, sons fônicos, as letras iniciais de qualquer palavra como leitura de mundo" (Professora B). Em outro momento, a mesma professora registrou: "letrar seria iniciar o processo das letras na educação infantil e alfabetizar será a continuidade do letramento. Alfabetização, ao longo da vida" (Professora B); "é a identificação de fonema e grafema de forma esquematizada" (Professora E); "letramento pra mim é a construção da ideia da alfabetização. Inserção da criança no mundo das palavras" (Professora D). 
Nas respostas acima ficou evidente que as professoras não diferenciavam alfabetização e letramento. Tal qual no estudo de Berberian et al. (2013), as professoras não distinguiam as especificidades dos dois processos, que mesmo complementares, são distintos em relação às ações pedagógicas oferecidas às crianças. De acordo com Soares (2016), se por um lado letramento envolve práticas de leitura e escrita, a compreensão de textos e sua interpretação, funções da escrita; por outro, a alfabetização implica em apropriação do sistema alfabéticoortográfico e das convenções da escrita.

As atividades propostas para as crianças que foram analisadas, durante o estudo, se centravam no reconhecimento de letras, os seus respectivos nomes e na grafia das mesmas. A ordem das letras era definida pelo grupo de professoras, que buscavam em arquivos anteriores ou na internet tarefas vinculadas a elas. Não havia clara relação com os interesses das crianças, nem com as suas curiosidades. Ao contrário, o foco ainda era a letra e o seu traçado, em um processo que visava favorecer a alfabetização futura dos estudantes.

Nesse sentido, ressaltam-se as contribuições de Alburqueque e Leite (2018), que afirmam: apesar de ser um conhecimento necessário, a aprendizagem das letras não é suficiente para que as crianças se apropriem da escrita alfabética e consigam, assim, ler e escrever com autonomia.

Além disso, verificou-se também as construções acerca da alfabetização, implícitas em suas colocações: "alfabetizar é ler letras" (Professora C); "alfabetização pra mim é a inserção da criança no universo da leitura" (Professora D); e, "no letramento a criança percebe esse esquema e na alfabetização é quando se há a transformação desse esquema numa significação escrita e oral" (Professora E).

As respostas das professoras indicaram o entendimento da alfabetização em seu sentido etimológico, isto é, "levar à aquisição do alfabeto" (SOARES, 2012, p.15). As atividades envolviam o traçado das letras, segundo os pontilhados, e o treino da grafia. As palavras que serviam de referência para o estudo das letras, partiam das escolhas das professoras e suas preferências temáticas - assuntos para abordarem no trabalho pedagógico.

Os murais das salas de aula, também, se restringiam as atividades cotidianas, como: chamada, com fichas dos nomes; quantos somos, para a contagem das crianças presentes e ausentes, e os combinados, regras de convivência da turma. Todos os materiais produzidos pelas 
professoras, sem a participação das crianças em sua confecção e uso diário. Não foi observado o uso de textos, cartazes produzidos pelas crianças ou outros suportes textuais.

Entretanto, ao responderem à questão acerca da possibilidade de letramento na educação infantil, as professoras registraram: "sim, porque essa ideia de letras e palavras é construída muito cedo, desde o primeiro contato com as letras (nome, palavras etc.)" (Professora D); “sim, as crianças compreendem, entendem a realidade em que vivem" (Professora C); e, "Sim, porém de forma lúdica é mais divertido" (Professora B). Em suas respostas as professoras demonstraram que acreditam no papel ativo das crianças e que elas são capazes de entender o universo da cultura escrita.

\section{Considerações finais}

O estudo realizado partiu da compreensão de que as práticas de letramento não dependem do processo de alfabetização. Há relações, aproximações e distinções entre os dois conceitos, que se inter-relacionam no trabalho pedagógico desde a educação infantil. Por isso, trabalhar textos, sua construção, interpretação e funções pode ser relevante para as aprendizagens, também, das crianças de quatro e cinco anos de idade. Estas, mesmo sem plena apropriação do sistema de escrita alfabética, podem ser beneficiar as diferentes possibilidades de leitura e escrita.

Nesse sentido, esse estudo exploratório teve objetivo investigar o que as professoras de educação infantil compreendem a respeito do letramento. Para tanto, partiu-se do entendimento de que a primeira etapa da educação básica possui uma especificidade pedagógica, que implica em uma formação cultural própria e segundo o momento do desenvolvimento das crianças, consequentemente, envolve o letramento em língua portuguesa. O letramento, por sua vez, foi entendido como os diferentes usos sociais das práticas de leitura e escrita, abrangendo formas visuais diversas e todo tipo de expressão visual e pictográfica.

Assim, considerando as informações construídas na pesquisa, foi possível compreender que:

a) Para as professoras da educação infantil participantes da pesquisa prevaleceu a função socializadora do atendimento pedagógico às crianças, apesar de reconhecerem que a etapa é importante para as aprendizagens dos estudantes. 
b) As professoras que atuam na educação infantil confundem os conceitos de letramento e alfabetização e não esclarecem as diferenças entre os dois processos, suas relações e interações na aquisição da aprendizagem inicial da língua escrita.

As construções desse estudo conduzem as diferentes possibilidades explicativas, que permitem outras investigações. Entre as alternativas está a formação docente no que se refere especificamente à educação infantil e as práticas de letramento, e que podem ocorrer tanto em espaços formais/institucionais, como nos momentos de planejamento e coordenação pedagógica. Dessa forma, surgem outros questionamentos: será que a formação inicial contempla as especificidades da educação infantil? A formação continuada oportuniza aos professores discussões acerca da função social da primeira etapa da educação básica? E mais, os professores atuantes na educação infantil têm oportunidades formativas a respeito do letramento?

Diversas questões estão atreladas as construções dessa pesquisa. O tema é vasto e ainda há muito para avançar no que se refere ao trabalho pedagógico na educação infantil, as suas especificidades e o letramento. Omitir discussões a respeito do caráter educativo do atendimento aos estudantes de quatro e cinco anos colabora para uma série de entraves que vão se constituindo desde a entrada das crianças no sistema de ensino. É, relevante, assim, outros estudos e pesquisas que contemplem a primeira etapa da educação básica.

\section{Referências}

ALBUQUERQUE, E. B. C.; LEITE, T. M. R. Explorando as letras na educação infantil. In: BRANDAO, A. C. P.; ROSA, E. C. S. (orgs.). Ler e escrever na educação infantil: discutindo práticas pedagógicas. 2. ed. Belo Horizonte: Autêntica, 2018, p.93-115.

BARRETO, A. M. R. F. Educação infantil: crenças sobre as relações entre práticas pedagógicas específicas e desenvolvimento da criança. 2004. 308f. Tese (Doutorado em Psicologia) Universidade de Brasília, Brasília, 2004.

BARROS, M. T. A.; SPINILLO, A. G. Contribuição da educação infantil para o letramento: um estudo a partir do conhecimento de crianças sobre textos. Psicol. Reflex. Crit. v.24, n.3, p.542550, 2011 [online]. Disponível em: https://www.scielo.br/pdf/prc/v24n3/a15v24n3.pdf. Acesso em: 30 mar. 2020. 
BERBERIAN, A. P. et al. Análise do conhecimento de professores atuantes no ensino fundamental acerca da linguagem escrita na perspectiva do letramento. Rev. CEFAC, v.15, n.6, p.1635-1642, 2013 [online]. Disponível em: https://www.scielo.br/pdf/rcefac/v15n6/21911.pdf. Acesso em: 30 mar. 2020.

BRANDÃO, A. C. P.; LEAL, T. F. Alfabetizar e letrar na educação infantil: o que isso significa? In: BRANDAO, A. C. P.; ROSA, E. C. S. (orgs.). Ler e escrever na educação infantil: discutindo práticas pedagógicas. 2. ed. Belo Horizonte: Autêntica, 2018, p.13-31.

BRASIL. Lei no 9.394, de 23 dezembro de 1996. Institui a Lei de Diretrizes e Bases da Educação Nacional. Estabelece as diretrizes e bases da educação nacional. Brasília, DF. Diário Oficial [da] República Federativa do Brasil. Brasília, DF, Seção 1, p.27-833.

BRASIL. Resolução CNE/CP 1, de 15 de maio de 2006. Diretrizes Curriculares Nacionais para o curso de Pedagogia. Diário Oficial da União, Brasília, 16 maio 2006, Seção 1, p.11. Disponível em: www.mec.org.br. Acesso em: 26 mar. 2020.

BRASIL. Ministério da Educação. Diretrizes curriculares nacionais para a educação infantil. Secretaria de Educação Básica. - Brasília: MEC, SEB, 2010.

BRASIL. Lei n. 13.005, de 25 de junho de 2014. Aprova o Plano Nacional de Educação - PNE e dá outras providências. Diário Oficial da União: Brasília, 26 junho 2014.

BRASIL. Base Nacional Comum Curricular [última versão]. Brasília: MEC/CONSED/UNDIME, 2017. Disponível em:

http://basenacionalcomum.mec.gov.br/images/BNCC_EI_EF_110518_versaofinal_site.pdf. Acesso em: 30 out. 2020.

CORRÊA, M. T. O. Avaliação e a qualidade da educação infantil: uma análise dos processos avaliativos desenvolvidos na creche e na pré-escola. 2007. 248f. Dissertação (Mestrado em Educação) - Universidade de Brasília, Brasília, 2007.

GALVÃO, A. M. O. Crianças e cultura escrita. In: Ministério da Educação, Secretaria de Educação Básica (orgs.). Linguagem oral e linguagem escrita na educação infantil: práticas e interações. Brasília: MEC /SEB, 2016, p.15-41.

HADDAD, L. Substituir ou compartilhar? o papel das instituições de educação infantil no contexto da sociedade contemporânea. In: MACHADO, M. L. A. (org.). Encontros e desencontros em educação infantil. São Paulo: Cortez, 2005, p.91-96.

KRAMER, S. Direitos da criança e projeto político-pedagógico da educação infantil. In: BAZíLIO, L. C., KRAMER, S. Infância, educação e direitos Humanos. Campinas: Cortez, 2003, p.51-81.

KRAMER, S. Infância e currículo: paradoxos, mudanças e riscos. In: MOREIRA, A. F. B., ALVES, M. 
P.C.; GARCIA, R. L. (orgs). Currículo, cotidiano e tecnologias. Araraquara, SP: Junqueira \& Marin, 2006, p.197-214.

KUHLMANN JR., M. Educação infantil e currículo. In: FARIA, A L. G.; PALHARES, M. S.; MARTINEZ, C. M. S. Educação infantil pós-LDB: rumos e desafios. Campinas, SP: Autores Associados - FE/UNICAMP, 2003, p.51-65.

LÜDKE, M.; ANDRÉ, M. Pesquisa em educação: abordagens qualitativas. São Paulo: EPU, 1986.

MARCUSCHI, L. Oralidade e letramento como práticas sociais. In: MARCUSCHI, L.; DIONISIO, A. P.(orgs.). Fala e escrita. Belo Horizonte: Autêntica, 2007, p.31- 55.

MORAIS, A. G.; SILVA, A.; NASCIMENTO, G. S. Ensino da notação alfabética e práticas de leitura e escrita na educação infantil: uma análise das três versões da Base Nacional Comum Curricular. Rev Bras. Educ. Rio de Janeiro, v.25, 2020, p.1-25. Disponível em:

$<$ http://www.scielo.br/scielo.php?script=sci_arttext\&pid=S141324782020000100219\&lng=en\&nrm=iso >. Acesso em: 30 out. 2020.

OLIVEIRA, Z. M. R. Os primeiros passos da história da educação infantil no Brasil. In: OLIVEIRA, Z. M. R. Educação infantil: fundamentos e métodos. São Paulo: Cortez, 2002, p.89-105.

OLIVEIRA, Z. M. R. Creches no sistema de ensino. In: MACHADO, M. L. A. (org.). Encontros e desencontros em educação infantil. São Paulo: Cortez, 2005, p.79-82.

ROCHA, E. A. C. Crianças e infâncias: uma categoria social em debate. Rev Zero a Seis, v.6, n.9, p.15-20, 2004 [online]. Disponível em:

https://periodicos.ufsc.br/index.php/zeroseis/article/view/10152/9388. Acesso em: 25 mar 2020.

ROSEMBERG, F. Do embate para o debate: educação e assistência no campo da educação infantil. In: MACHADO, M. L. A. (org.). Encontros e desencontros em educação infantil. São Paulo: Cortez, 2005, p.63-78.

SOARES, M. Alfabetização e letramento. 5. ed. São Paulo: Contexto, 2007.

SOARES, M. Letramento: um tema em três gêneros. Belo Horizonte: Autêntica, 2012.

SOARES, M. Alfabetização: a questão dos métodos. São Paulo: Contexto, 2016.

YIN, R. K. Estudo de caso: planejamento e métodos. 3. ed. Porto Alegre: Bookman, 2005.

Recebido em março 2020.

Aprovado em janeiro 2021.

Periódico Horizontes - USF - Itatiba, SP - Brasil - e021005 